\title{
Educating Silicon Valley: corporate education reform and the reproduction of the techno-economic revolution
}

\author{
Ben Williamson, Faculty of Social Science, University of Stirling
}

[Pre-publication version of paper accepted in Review of Education, Pedagogy \& Cultural Studies]

\begin{abstract}
Silicon Valley is seeking to reform education in its own image, as part of a 'techno-economic revolution' that is spreading globally. This essay provides an original analysis of how Silicon Valley is seeking to reproduce its centrality to the techno-economic revolution through technology-based reformatory efforts in education. In so doing, it is becoming a major influence in corporate education reform, seeking to take its new pedagogic practices, technical platforms and economic models to the reform of state education at massive scale.
\end{abstract}

Keywords corporate education reform, educational technology, information capitalism, Silicon Valley

Critical cultural and sociological studies of education have been concerned for the last half century with how the knowledge, interests and culture of powerful social actors are reproduced through the institutions of education. Recently, education has become the focus of significant interest in Silicon Valley, the world's most successful site of technical and economic innovation. Established Silicon Valley technology companies, wealthy philanthropic entrepreneurs, venture capital investors and new startup organizations have become committed to educational innovation and reform particularly since 2012. That year saw the publication of a report by Global Silicon Valley (a merchant bank that has advised, invested in and accelerated many technology companies) entitled American Revolution 2.0 that described key technical catalysts for educational transformation and reform - such as cloud computing, wired classrooms, low-cost hardware and software - and estimated the K-12 education market to be worth over $\$ 2.2$ trillion (Bulger, McCormick \& Pitcan 2017). As a result, a distinctive approach to education has emerged within Silicon Valley itself. New kinds of institutions, practices, partnerships and funding models have been developed and are being trialed and tested, in the hope that these will provide effective educational approaches that might be 'scaled up' to other geographical, social and demographic sites. Though 'venture philanthropy' has been associated with forms of 'corporate education reform' since the 1990s (Saltman 2010), the new Silicon Valley venture philanthropists, and the projects they promote and invest, take software development and computational products as the model for the future practices of education. They are prototyping these products and practices within the educational landscape of Silicon Valley itself, and seeking to extend them to the practices, institutions and governance of public education itself.

Silicon Valley's high-tech companies, tech-philanthropists, startups and culture of venture capital are 'the centre of a techno-economic revolution' that is 'now spreading outwards across the world, with major societal effects and implications' (Duff 2016, 5). In this essay I trace and map how education is being reimagined in Silicon Valley to address how it is seeking to reproduce its centrality to the techno-economic revolution. In other words, what are Silicon Valley's distinctive 
pedagogies, and to what purposes are they being put? In the first part of the essay, I describe the underlying Silicon Valley politics that shape its outlook toward education, then present a series of documentary studies of specific Silicon Valley educational innovations: (1) student-centred hightech homeschooling approaches involving 'hackerspaces,' (2) the building of 'startup schools' as a new model of 'administrative progressivism'; (3) the role of Stanford University in training web platform designers who can influence public opinion through persuasive computing; (4) the growth of 'teen technorati' programs for Silicon Valley apprenticeship; and (5) the growth of distinctive Silicon Valley self-help training courses for psychological self-improvement and the building of human capital. The conclusion reflects on how Silicon Valley is seeking to reproduce its centrality to the techno-economic revolution through its reformatory efforts in education. In so doing, it is becoming a major influence in corporate education reform, seeking to take its new pedagogic practices, institutions and technical platforms for a reformed education to massive scale across public education.

Before proceeding, a note on geography. Defined geographically, Silicon Valley encompasses part of the east Bay Area of San Francisco and runs south through Santa Clara valley to include San Jose, Stanford, Mountain View, Cupertino and Palo Alto, plus adjacent parts of San Mateo, Alameda and Santa Cruz counties. Primarily, however, Silicon Valley describes the kind of industry and culture that inhabits the area rather than a specific geographical zone. Duff (2016, 14) claims it parades itself as a 'technopolis,' simultaneously the headquarters of the information revolution, an identifiable social and cultural community, a physical space with borders, and 'a peculiar "state of mind" too.' Likewise, Castells $(1996,54,57)$ has described Silicon Valley as a 'milieu of innovation' and a 'social, cultural and spatial pattern of innovation' that is characterized by the continuous creation of startup firms, rapid knowledge diffusion and ideasexchange, spatial concentration of research centres, business networks of venture capital and finance startups, and loose social clubs where software developers and designers can share ideas and information. Lewis-Krause (2016) claims that the 'most important thing happening in Silicon Valley right now is ... institution-building — and the consolidation of power-on a scale and at a pace that are both probably unprecedented in human history' that involves 'major investments in human cultivation.' Silicon Valley has, then, positioned itself as the centre of a technical revolution - 'executed with bits, algorithms, code, telecoms, expert systems, AI, ... and covering everything from the acquisition and storage of data to retrieval, distribution, and consumption'but also an economic revolution in 'information capitalism', an unusual mixture of standard capitalist practice such as profit-seeking and efficiency, with the idealism of sharing and community values (Duff 2016, 13). Silicon Valley can also be variously characterized as libertarian, individualistic, pseudo-spiritual, utopian, and hubristic, with seemingly contradictory hybrids of cultural bohemianism and hippie radicalism working alongside conservative economics and an extreme work ethic.

These characteristics of Silicon Valley have wrought changes on the geographical landscape it occupies, as the techno-centred cultures and material practices of young, urban Silicon Valley workers have shaped the spaces they inhabit. Ferenstein (2015) has described Silicon Valley as a socio-demographic zone characterized more by the politics of the technology sector than its geography, albeit a form of politics that is soaking into the geographical landscape in the shape of urban expansion and the regeneration of urban areas to suit the lifestyles of youthful tech sector workers. Its culture and political outlook are also, like its products, spreading to other 
zones, as its 'growing demographic of highly-skilled college-educated liberals will transform government's role to be about directly investing in citizens, funding them to become as entrepreneurial, civic, and healthy as possible' (Ferenstein 2015). These Silicon Valley liberals mix libertarianism with Democratic political convictions, which leads to extreme idealism about human nature, society, and the future as well as a rejection of the notion that there are inherent conflicts of interests between citizens, the government, corporations or other nations. Ferenstein terms the new Silicon Valley liberals 'civicrats,' or 'tech-Democrats,' whose goal is to make everyone innovative, healthy, civic and educated, prefer that the government be run like a business and a competitive marketplace, and see government's role as an investor in maximizing people's contribution to the economy and society. It is this civicratic mentality that is shaping Silicon Valley itself, and via its technical products percolating out into the culture and society at large. These ways of thinking in Silicon Valley have sedimented over decades since the first silicon chip innovators established there, and have been powered by the media, US government spending, and venture capital, as well as through initial leadership by Stanford University (Castells 1996). As a consequence, Silicon Valley is now governed according to a particular set of powerful ideas that animate its economic ambitions, its technological solutionist culture, and its particular brand of political conviction, and that are also catalysing shifts in everyday practices across society, not least in relation to its interests in education.

\section{Startup education ministries}

Silicon Valley has significant interests in education as the 'epicenter of technological optimism' (Cuban 2016). On one level, its interests simply reflect market opportunities and business plans-education is a big market, and certain Silicon Valley educational technology products have quickly spread worldwide. According to some sources, technology companies are investing with unprecedented enthusiasm in 'ed-tech,' with an estimated \$2.3billion USD of venture capital invested in education technology companies in the K-12 space in the US between 2010 and 2015 (EdSurge 2016). Venture capital funding tends to be awarded as seed funding for new startups, early stage investment, or expansion investment, and by 2015 was consolidating around expansion stage funding in a direct challenge to the existing monopoly over educational technology by big publishers such as Pearson, Houghton Mifflin Harcourt, and McGraw-Hill. One venture capitalist quoted in a magazine article on Silicon Valley's educational ambitions has noted that education 'is an industry that is measured in the trillions of dollars, not billions; it's multiple percentage points of gross domestic product. The consumption of this product is required for a meaningful portion of our population' (Kuchler 2017). Notably, Silicon Valley has its own educational technology news and media source, EdSurge, 'to connect the emerging community of edtech entrepreneurs and educators' and help 'entrepreneurs who build new products and businesses, educators who use these tools, and investors and others who support companies and schools' (http://about.edsurge.com/). The growth of venture capital support for education via Silicon Valley makes financial revenue generation, measurable returns on investment, and path to profitability into decisive factors shaping education reform.

Its interests in education are also, though, more political than merely commercially ambitious. In a recent study of the political outlook of Silicon Valley's technology elite, Ferenstein (2015) has identified key educational features of a 'Silicon Valley ideology': 
The Silicon Valley ideology thinks about government as an investor rather than as a protector, arguing that the government's role is to invest in making people as awesome as possible. Silicon Valley wants to make people in general educated and entrepreneurial. (Lee \& Ferenstein 2016)

Notably, Silicon Valley ideologues see education as the solution to major social, political and technological problems. Many Silicon Valley startup founders 'believe that the solution to nearly every problem is more innovation, conversation or education,' and therefore 'believe in massive investments in education because they see it as a panacea for nearly all problems in society' (Ferenstein 2015). They particularly like performance-based funding systems like charter schools as educational alternatives that can operate free of centralized government regulation and teachers' unions, and want the government to be run like a business and a competitive marketplace, preferring competition among public services:

This helps explain why tech elites, including Bill Gates and Mark Zuckerberg, have given hundreds of millions of dollars to charter schools. Charters are often highly experimental, union-less public schools that are managed by performance-based metrics. Indeed, the federal education law, itself, Race to the Top, is basically a giant prize competition, which awards a greater share of federal dollars to schools and districts that outperform their peers. (Ferenstein 2015)

US charter schools enable private organizations to penetrate the publicly funded education sector, govern institutions directly, and to advocate more competitive, deregulated models for public education, thus 'serving as a vehicle for privatizing public policy—diminishing the public while enhancing the position and influence of private interests and organizations in education policymaking' (Lubienski 2013, 498). As Saltman (2010: 33) has demonstrated, Silicon Valley entrepreneurs such as Bill Gates have actively sought to intervene in public education through venture philanthropies such as the Bill and Melinda Gates Foundation, 'the largest player in a fundamental transformation of education philanthropy: it is setting the agenda for modelling public education in the United States on venture capital.' Philanthropies such as the Gates Foundation are seeking to replace public education with privatized educational provision, mobilizing techniques of goodwill, care and generosity to 'redistribute control from teachers, parents, students and communities to private foundations, for-profit and non-profit organizations, business groups, and investors' (Saltman 2010: 35). A particular politics therefore underpins Silicon Valley's approach to education, one which emphasizes the centrality of education to innovation and to the creation of 'awesome,' entrepreneurial individuals, and the establishment and support for competitive models of education that can be measured and rewarded based on performance toward these goals.

The nexus of commercial Silicon Valley technology companies with education is part of a broader 'restructuring of public education by economic and political elites' which have 'succeeded in strategically advancing privatization and market-based school "reforms" to transform public education into a private industry while also hijacking public governance over educational policy' (Saltman 2016, 107). A particularly notable example of Silicon Valley ambitions for education is that of the Chan Zuckerberg Initiative (http://chanzuckerberg.com/), set up by Facebook founder Mark Zuckerberg with his wife Priscilla Chan as 'a limited liability corporation ... free to make philanthropic donations, invest in for-profit companies, and engage in political lobbying and policy advocacy' (Herold 2016). The philanthropic organization has been established after Zuckerberg and Chan announced in 2015 their intention to give away 99\% of their Facebook stock, valued at around $\$ 45 \mathrm{bn}$ USD, to a variety of causes-including 
technology-enabled 'personalized learning' in K-12 education. The head of the educational arm of the initiative has been announced as James Shelton, former US Deputy Secretary of Education who has also previously worked as a program director at the Bill \& Melinda Gates Foundation and as a partner at the NewSchools Venture Fund, both of which have donated and invested heavily in education technology, charter schools and other new school models. Zuckerberg and Chan have also established a series of for-profit and non-profit organizations as part of 'a new, multi-pronged effort to use their massive fortune to reshape public education with technology' (Education Week 2016), including a partnership with Summit Public Schools, which has metamorphosed from a single school in Silicon Valley to a Summit Personalized Learning Platform used by 20,000 students across 27 US states (Kuchler 2017).

The Chan Zuckerberg Initiative exemplifies how education has become infused with a form of 'Californian capitalism' that privileges a 'programmer mindset' toward solving computational problems, entrepreneurialism, and 'making a difference' while making a profit, all of it fuelled by similarly 'computer-savvy venture capitalists and "angel investors"' (Selwyn 2016, 114-115). Consequently, Silicon Valley companies are becoming 'shadow education ministries' (Selwyn 2016, 131) with the entrepreneurial capacity to set reformatory agendas for contemporary education. Although venture philanthropies have long sought to interfere in public education through charter schools, the new Silicon Valley venture philanthropists are seeking more overtly computational models of education reform which utilize the technical expertise of Silicon Valley itself to design new software systems and technological fixes for insertion into the institutions of education. The business model for venture philanthropy has been subtly modified to emphasize not just infrastructural change in the shape of charter schools, market-based reforms and competition, but also to prioritize data-driven personalized learning technologies within alternative private and charter school models.

Although most of the Silicon Valley reforms detailed below remain confined to the Valley itself_-as a mechanism for reproducing its centrality to techno-economic innovation-the ambitions of the new startup education ministries are to take its new models to larger scale, and in this way to adopt a disruptive role in relation to state education as a whole. In this sense, the particular politics associated with what has been variously termed the techno-economic revolution, Silicon Valley ideology, or Californian capitalism are being prototyped within Silicon Valley as a beta-test for massively scaled-up disruptive innovations in state education.

To be clear, the argument developed in this article is that Silicon Valley is seeking to develop its vision for education by enrolling various allies and intermediaries to subscribe to and support its own norms, ambitions and actions. As the following documentary analyses show, Silicon Valley has successfully juxtaposed the student-centred progressivist philosophy of homeschooling on to its technocratic vision; it has latched on to the US charter schools agenda to launch its own startup schools; its interests are integrated into prestigious teaching and research centres such as Stanford University; it has generated new entrepreneurial apprenticeship programs and fellowships through its philanthropic donors; and it has become entwined with the therapeutic culture of self-help training curricula associated with behavioural economics. In each of these relationships, various technical systems, materials and texts play key roles, and become part of a network of coordinated activity. Through the enrolment of these diverse educational practices, material resources and approaches, Silicon Valley is both seeking to reproduce itself by training 
up the innovative human capital required to sustain its centrality to a techno-economic revolution, but also to build new models of education that might be 'scaled-up' as a disruption to state education itself. Rather than cumbersome bureaucracy, regulation and regimes of accountability that constrain public education, it is seeking to promote glossy, attractive and innovative alternatives that might persuade diverse publics and funding sources to support their growth as scalable solutions to the problems of state schooling.

\section{Student-centred learning through high-tech homeschooling}

In response to perceived failures of public education, many Silicon Valley coders, hackers and makers are now choosing to educate their own children at home. A recent article in Wired (Tanz 2014) has profiled a new breed of 'techie' homeschooler parents who see public or state education as fundamentally broken, and have chosen instead to educate their children themselves. The Silicon Valley homeschooler is not the fundamentalist activist of liberal stereotyping. Instead, the high-tech homeschooler sees 'makerspaces' and 'hackerspaces' as ideal kinds of educational institutions, where children can learn directly through digital tinkering, hacking, coding and making, rather than through the prescriptive, standardized model of state schooling. Makerspaces and hackerspaces are part of a growing global 'maker movement' that consists of activities such as writing computer code, programming apps, digital fabrication, 3D printing, crafting products, and personal manufacturing, as well as extending to 'civic hacking' and 'coding for civic service' to make new digital services to improve social life.

The new Silicon Valley high-tech homeschoolers blend the approach of makerspaces and hackerspaces with a much longer lineage of progressivist education that includes such important 'deschooling' figures as Ivan Illich and 'unschoolers' such as John Holt. Halverson and Sheridan (2014) note that the 'maker movement' has emerged from the progressivist tradition of constructionism and constructivist learning theory twinned with entrepreneurial discourses of 'the next industrial revolution' propagated by technology evangelists such as former editor-inchief of Wired, Chris Anderson. The deschooling and unschooling movements fundamentally saw schools as overly constrictive, and advocated instead for learners to engage in more selfdirected education in real-life settings and social networks. Suoranta and Vaden $(2010,177)$ have articulated the idea of an 'educational superabundance' associated with online learning networks that are inspired by the apparent freedom of Illich's 'learning webs.' This is an irresistible invitation for Silicon Valley ideologues when it comes to rethinking education.

Through the convergence of Silicon Valley politics and progressivist thinking, the new high-tech homeschoolers represent a new breed of unschoolers:

They don't prefer homeschooling simply because they find most schools too test-obsessed or underfunded or otherwise ineffective. They believe that the very philosophical underpinnings of modern education are flawed. Unschoolers believe that children are natural learners; with a little support, they will explore and experiment and learn about the world in a way that is appropriate to their abilities and interests. Problems arise, the thinking goes, when kids are pushed into an educational model that treats everyone the samegives them the same lessons and homework, sets the same expectations, and covers the same subjects. (Tanz 2015a)

The rise of this kind of thinking has been associated with heightened political support for homeschooling through powerful advocacy coalitions (Lubienski, Puckett \& Jameson Brewer 2013), but also with the 'shadow schooling' of private supplementary tutoring (Bray \& Kwo 
2013). The key point here is that high-tech homeschooling through makerspaces represents a convergence of progressivist discourses of education with 'shadow' models of education and with the kinds of ideologies emanating from Silicon Valley. As Watters (2015) asks:

How does a push for 'self-directed learning' feed a libertarian anti-institutionalism? How does the mantra 'everyone needs to learn to code' serve the interests of global capitalism? How much of the 'Maker Movement' is venture-backed consumerism? What does it say that this profitable version of 'making' dovetails so neatly with some visions of progressive education?

One way of educating Silicon Valley, then, is through high-tech homeschooling and hackerspaces, under the guise of a progressive learner-centred discourse. Homeschooling is one part of an emerging consensus in the valley that state schooling is broken and that alternative practices and institutions are required.

\section{Administrative progressivism in startup schools}

A notable educational development around Silicon Valley is the establishment of new 'startup schools,' recently profiled by the Financial Times as 'Silicon Valley's classrooms of the future' (Kuchler 2017). Capitalizing on the opportunities presented by US charter schools policy, Silicon Valley's new startup schools are primarily fee-paying and performance-measurement models. The prominent startup school example is AltSchool (https://www.altschool.com/), set up in 2013 by Max Ventilla, a former tech entrepreneur and Google executive, which 'prepares students for the future through personalized learning experiences within micro-school communities.' Its stated aim is to 'help reinvent education from the ground up.' After establishing in four sites in San Francisco as a 'collaborative community of micro-schools,' AltSchool expanded in September 2015 to Brooklyn and Palo Alto, with further plans for new schools in 2016. It has since hired executives from Google and Uber plus other successful Silicon Valley startups, and in 2015 received \$100million USD venture capital, the largest educational technology deal in K-12 education of the year.

The AltSchool chief technology officer, formerly the engineer in charge of the Google.com homepage and search results experience, has stated that 'I am highly motivated to use my decade of Google experience to enable the AltSchool platform to grow and scale.' Elsewhere on the AltSchool site, the AltSchool 'platform' is described as a new 'central operating system for education,' a technical system that can be scaled to new sites. AltSchool is, in other words, both a private school and a software development company. Its platform primarily consists of a powerful software aggregation and data analytics tool which:

pulls in assessments from individual student work, projects, and 3rd party standards, forming a comprehensive view of a student's progress in each area. An educator can quickly see where a student has demonstrated mastery and where they need to improve specific skills.

As a software platform, AltSchool is managed on analytical, technical and scientific lines, albeit laced with the progressivist discourse from which it draws its central philosophy. As Lapowsky (2015) characterizes it in a recent profile of AltSchool in Wired magazine:

AltSchool is a decidedly Bay Area experiment with an educational philosophy known as student-centered learning. ... To that, however, AltSchool mixes in loads of technology to manage the chaos, and tops it all off with a staff of forward-thinking teachers set free to custom-teach to each student. ... This puts AltSchool at the intersection of two rapidly growing movements in education. Along one axis are the 
dozens of edtech startups building apps for schools; along the other are the dozens of progressive schools rallying around the increasingly popular concept of personalized education.

Self-described as a 'full-stack education company,' AltSchool is staffed equally by engineers, educators and business managers, and 'parents pay fees, hoping their kids will get a better education as guinea pigs, while venture capitalists fund the R\&D, hoping for financial returns from the technologies it develops' (Kuchler 2017). Silicon Valley has adopted the progressivist discourse of personalized education both as a justification for classroom experimentation and as the basis of its business plan.

Notably, AltSchool's founder, Max Ventilla, was formerly head of 'personalization' at Google. He was one of the key executives responsible for Google Now, the service that tracks its users' online activities, location and communication data in order to provide algorithmically-automated digital experiences. As an ideal, personalization has captured the imagination of new educational technology startup companies and venture capital investors alike (Corcoran \& Gomes 2016). Personalization has become a significant concept for schools such as AltSchool, which merges the progressivist emphasis on student-centredness with the social media technique of wrapping customized digital experiences delivered to individual users based on big data analytics. RobertsMahoney, Means and Garrison (2016: 2) have tracked the emergence of a political discourse around big data analytics in K-12 education in the US, critically analyzing policy documents related to the emerging 'personalized learning technologies' of big data mining, algorithmic computation, learning analytics, and adaptive learning systems according to the values and assumptions that animate their use and define their purpose:

\footnotetext{
Advocates for personalized learning technology ... suggest that if digital platforms such as Google, Netflix, Amazon, and Facebook have transformed the way we conduct business, work, shop, communicate, travel, organize, and entertain one another, then it only makes sense to apply the operational logics of these platforms to educational systems in the name of progress and innovation.
}

These authors see data-driven technologies as part of a 'corporate school reform' movement that emphasizes market competition and business management as the key to educational improvement. Ultimately, as an adaptive learning software platform based on corporate school reform aspirations, AltSchool translates the social media personalization experience, and specific technical systems, into the progressivism of student-centred experiential learning, in ways which 'position teaching and learning within a reductive set of economic goals and purposes that emphasize human capital development and training future workers ... [and] advocate for the expansion of data-driven instruction and decision-making' (Roberts-Mahoney, Means \& Garrison 2016: 2).

Other startup schools that similarly hybridize student-centred progressivism with technical platforms for personalization include The Primary School (https://www.theprimaryschool.org/), currently being set up by Mark Zuckerberg and Priscilla Chan, and The Khan Lab School (http://khanlabschool.org/), established by Salman Khan of the online Khan Academy. The Khan Lab School (which consciously echoes John Dewey's experimental Lab School at the University of Chicago) specializes in math, literacy and computer programming - in line with its tech sector roots-but also emphasizes 'real world' projects, character development, personalization, student-centred learning, and a strong commitment to building children's 'character' and 'wellness' through, for example, 'mindfulness' meditation training. Like 
AltSchool, though, its 'touchy feely' surface of character-centred learning is combined with analytics tools for 'tracking data about every dimension of a student's scholastic and social progress' (Tanz 2015b). Khan Lab School and AltSchool are 'mini-research and development labs, where both teachers and engineers are diligently developing the formula for a 21 st century education, all in hopes of applying that formula ... to private, public, and charter schools across the country' (Lapowsky 2015).

According to a study of technology-enhanced personalized learning in Silicon Valley schools by Cuban (2016), the Silicon Valley brand of progressivism is closer to that of efficiency-minded, 'administrative progressives,' whose approaches seek to emulate the practices of corporate leaders of large organizations committed to both efficiency and effectiveness, than to Dewey's form of democratic education. This reflects a long history of competing forms of progressivism in education, so that while 'one wing of these early progressives were pedagogical pioneers advocating project-based learning, student-centered activities, and connections to the world outside of the classroom,' the administrative progressives 'counted and measured everything in schools and classrooms under the flag of "scientific management":

They reduced complex skills and knowledge to small chunks that students could learn and practice. They wanted to make teachers efficient in delivering lessons to 40-plus students with the newest technologies of the time: testing, film, radio. They created checklists for teachers to follow in getting students to learn and behave. They created checklists for principals to evaluate teachers and checklists for superintendents to gauge district performance including where every penny was spent. ... What exists now is a re-emergence of the efficiency-minded 'administrative progressives' from a century ago who now, as entrepreneurs and practical reformers want public schools to be more market-like where supply and demand reign, and more realistic in preparing students for a competitive job market. (Cuban 2016)

Acting as pioneers of the new hybrid form of both student-centred and market-focused administrative progressivism, Silicon Valley is actively involved in funding and investing in these new models of schooling. Facebook's Mark Zuckerberg has invested \$15 million in AltSchool through his for-profit Zuckerberg Education Ventures organization, as well as establishing a nonprofit organization known as Startup:Education to channel $\$ 120$ million for Bay Area schools and millions more to support charter-school growth. Zuckerberg also established the Silicon Valley Community Foundation, which has funded the establishment of The Primary School. Other funding sources include the venture philanthropic Silicon Schools Fund (http://www.siliconschools.com/), which 'provides seed funding for new blended learning schools that use innovative education models and technology to personalize learning.' Its vision is of:

- Schools that give each student a highly-personalized education, by combining the best of traditional education with the transformative power of technology

- Students gaining more control over the path and pace of their learning, creating better schools and better outcomes

- Software and online courses that provide engaging curriculum, combined with real-time student data, giving teachers the information they need to support each student

- Teachers developing flexibility to do what they do best - inspire, facilitate conversations, and encourage critical thinking

In addition, in 2015, Laurene Powell Jobs (the widow of Steve Jobs, former head of Apple) granted a $\$ 50$ million philanthropic donation to a crowdsourced school redesign project. The XQ 
Super School Project (https://xqsuperschool.org/) is a competition to redesign the American high school, which it sees as a 'dangerously broken' social institution. The program is directed by Russlynn Ali, a former assistant secretary in the US Department of Education. Powell Jobs also invested in AltSchool during a venture capital funding round in 2015. Like the Silicon Schools Fund, her Super School Project is emblematic of Silicon Valley efforts to invest in education through venture philanthropic means, the role of wealthy tech-entrepreneurial individuals in the attempt to 'fix' schools and the 'failed system' of schooling, and the increasing blurring of lines between Silicon Valley entrepreneurship and education policy. These declarations of 'failure' represent an assault on the public sector and its 'failed systems,' and thus 'naturalize private enterprise as the cure to public schools "failings"” (Saltman 2010: 37), as well as proposing new 'technical fixes' for intractable social problems.

Positioned as technical fixes, programs such as AltSchool and XQ Super School Project provide a template for school reform that includes 'transformative' technology solutions, real-time data monitoring and measurement, and personalized learning supported by online courses and smart analytics. They are part of a 'growing movement' among powerful educational technology companies, supported by the US Department of Education and mediated through philanthropic organizations, to 'create "personalized learning" in K-12 education,' which reflects 'narrow corporate-driven educational policies and priorities such as privatization, standardization, highstakes assessment, and systems of corporate management and accountability' (Roberts-Mahoney, Means and Garrison 2016, 1-2). Startup schools might be seen as alternative shadow schools that challenge the supposed bureaucratic standardization of public education. These schools have mobilized the opportunity presented by US charter schools policies to create new institutions that lie outside of state regulation and control, and are committed to the rigorous scientific monitoring of their performance through techniques of data collection and analysis (Reckhow, 2013). They mobilize the child-centred progressivism of John Dewey and the ideal of personalized learning in ways that combine with the administrative progressivism of aggressive data collection about classrooms and students.

\section{Stanford, persuasive computing and political hackers}

Many Silicon Valley employees studied at Stanford University, one of the world's leading research and teaching universities and itself situated in the heart of the Valley. As Castells (1996) has noted, Silicon Valley at least partly owes its existence to the establishment of the Stanford Industrial Park by Stanford University in the early 1950s. Beyond geographical proximity, there has long been a revolving door between Stanford University and the Valley:

\footnotetext{
It's not only witnessed, but also notoriously housed, some of the most celebrated innovations in Silicon Valley. ... In return, its entrepreneurial alumni offer among the most generous endowments to the university, breaking the record as the first university to add more than $\$ 1$ billion in a single year. Stanford shares a relationship with Silicon Valley unlike any other university on the planet, chartering a selfperpetuating cycle of innovation. (Trikha 2015)
}

These tremendous endowments certainly confirm that Silicon Valley founders are committed to massive investment in education and innovation as a way of addressing social problems.

One of the most significant Stanford departments in the education of Silicon Valley software developers and designers is the Persuasive Technology Lab (http://captology.stanford.edu/). The lab aims to apply persuasive technologies to 'bring about positive changes in many domains, 
including health, business, safety, and education,' and 'creates insight into how computing products - from websites to mobile phone software — can be designed to change what people believe and what they do.' Some of Silicon Valley's most successful startup founders and app designers are alumni of the lab. They subscribe to its insights about designing technologies to create 'habit-forming products' - the title of a book by one of the lab's key researchers is Hooked: How to build habit-forming products_ —otherwise known as 'persistent routines' or 'behavioral loops.' The leading Stanford expert in persuasive computing is BJ Fogg, whose work on using computer design twinned with psychological insights to change what people think and do anticipated and deeply informed the social media explosion (Fogg 2002).

Silicon Valley companies such as Facebook, Twitter and Instagram have mastered the creation of habit forming products by basing their design on insights into human behaviour from behavioural economics and consumer psychology:

Designers can hook users through the application of psychological phenomena such as investment biasonce you've put time into personalizing a tool, you're more likely to use it. ... Another tool is rationalization, the feeling that if one is spending a lot of time doing something, it must be valuable. (Weisberg 2016)

Via Stanford's Persuasive Technologies Lab, behavioural economics is embedded in the education of Silicon Valley's young engineers. Behavioural economics has become a dominant influence on political thinking in the US and Europe in recent years, used as the basis for policy design and state intervention. The 'behaviour change agenda' is based on the assumption that human behaviour is largely habitual and predictable, and therefore manipulable, and has 'led to the gradual formation of new governmental programmes that seek to guide and compensate for the behaviours of the sub-optimal citizen' (Jones, Pykett \& Whitehead 2013: 3). Strategies to 'nudge' citizens' behaviours have become the focus for new state programs and other behaviour change initiatives. Stanford's expertise in persuasive computing represents how the psychological theories underpinning the behavior change agenda in the political domain have been translated into the design of digital habit-forming products. Yeung (2016) describes how such persuasive technologies exert 'hypernudges' which direct or guide the individual's decision-making processes in ways identified by the underlying software algorithm as 'optimal,' by offering suggestions intended to prompt the user to make decisions and therefore modify their behaviours. Through study at the Persuasive Technology Lab, young Silicon Valley developers and designers are educated into the behavioural and psychological tricks of hypernudging, influencing and persuading people to change their behaviours, in ways which hook users to their products but that might also be used to change other kinds of behaviours and opinions.

Stanford is also the home of a growing movement of political experimentation, where the politics of Silicon Valley are being designed into the training curricula of new kinds of policy designers and 'political hackers.' It is, for example, the scholarly home of Steve Hilton, a former senior adviser to British Prime Minister David Cameron, who now teaches at Stanford's Institute of Design. Credited as one of the major architects of the British Conservative Party approach to centre-right policy as well as the leading political advisor in the campaign for the UK to leave the European Union, and increasingly influential in US politics, Hilton is also the co-founder and CEO of Silicon Valley-based political tech start-up Crowdpac, a voter information and crowdfunding platform for politics (Wildman 2016). Hilton represents 'anti-institutional, anti- 
bureaucratic, pro-enterprise and pro-individualist attitudes' that emphasize marketization and the power of big data in political movements (Kane 2016), and demonstrates how Stanford has become a conduit for new kinds of political technologies that might shape public sentiment, opinion, and voting behaviours. The utilization of social media platforms as persuasive political technologies to subtly nudge public opinion is linked to technologies such as 'political bots'automated software programs designed to send out sophisticated computational propaganda (Woolley 2016)_ as well as techniques such as 'political hacking,' or the manipulation of social media to create false waves of enthusiasm and derision in political campaigns (Robertson, Riley \& Willis 2016). Notably, computational propaganda and the use of big data to analyse population sentiments and mobilize political movements have become a major concern since the US election of Donald Trump. Even the technology magazine Wired has acknowledged that Silicon Valley companies bear responsibility for the proliferation of 'fake news' and 'post-truth politics' over social media (Lapowsky 2016). Although Silicon Valley's politics tends to favour the Democratic party, the techniques of persuasive computing, digital hypernudging and hacking that it has refined via the pedagogic involvement of Stanford have contributed to deep political turbulence and public polarization.

Through influential figures such as BJ Fogg and Steve Hilton, and the research centres, institutions and spin-out startup companies they represent, Stanford has become a significant political influence both in major campaigns in the US and Europe, as well as more micropolitically in terms of nudging and influencing people's behaviours through persuasive technology platforms. Its specifically educational contribution is to train up new software developers, programmers, data analysts, and political thinkers who might turn their expertise to the shaping of people's behaviours and political opinions. In this sense, the practices of educating Silicon Valley through Stanford consist, in part, in the production of new kinds of persuasive programmers and political hackers who are able to mediate and shape public opinion through digital nudges. These alumni of Stanford are the political pedagogues of Silicon Valley, experts in the public pedagogies of social media and web platforms to re-educate citizens. In turn, many of its successful alumni are also providing Stanford generous endowments to ensure its continued relevance to the cycles of innovation required by the Valley to maintain its position as the epicentre of the techno-economic revolution.

\section{Training teen technorati as apprentice solutionists}

While higher education institutions such as Stanford clearly have a powerful role in educating Silicon Valley, other emerging organizations from within the Valley itself are beginning to challenge this status quo-indeed, many Stanford students do not even finish their degrees, preferring to establish their own startups instead. Much like the startup schooling movement, an entrepreneurial attempt to challenge the dominant approaches of higher education is also emerging. For example, 42 (https://www.42.us.org/) is a tuition-free university established in Silicon Valley to allow 'everyone to train themselves in IT development':

42's mission is to undercover the talents of their generation in the field of programming and to do so on a broad scale. To achieve this, 42 would like to give all young people an opportunity to learn to code. Students are selected neither on the basis of financial ability nor educational degree, but solely on the basis of their talent and motivation. By employing this new educational approach, 42 applies neither the academic nor the financial criteria that prevent too many of today's young people from achieving success. 
Pedagogically, 42 is based on the principle of peer-to-peer learning-as well as the 'maker' approach that underpins the 'learning to code' movement — and features no professors or classes, though its curriculum is determined by a Head of Pedagogy and a core pedagogical team. It is project-based rather than assessment-focused, and structured according to the rules of videogames_-students receive 'experience points' for project completion and can then unlock new challenges - which it terms 'progress gamification.' Notably, the 42 website features a number of videos of educational 'thought leaders' from glossy TED conferences to help explain its approach, as well as endorsements from many other high-profile Silicon Valley entrepreneurs, including Snapchat's Evan Spiegel, Facebook's David Marcus, and Twitter's Jack Dorsey. Established with $\$ 100$ million investment by French telecoms entrepreneur Xavier Niels, 42 is explicitly focused on upskilling young people to be productive and innovative workers for the software development marketplace in Silicon Valley, and serves as a pipeline model for industry that challenges the pedagogical approaches and financial demands of the conventional HE sector.

Other alternatives to traditional higher education routes in Silicon Valley are even more explicitly opposed to HE institutions. The Thiel Fellowship (http://thielfellowship.org/) program, established by PayPal founder Peter Thiel (another AltSchool investor and long-term Facebook board member), for example, proposes that educational institutions are entirely redundant when it comes to the meaningful education of young technology entrepreneurs. Each year, selected fellows of the program receive:

a grant of $\$ 100,000$ to focus on their work, their research, and their self-education while outside of university. Fellows are mentored by our community of visionary thinkers, investors, scientists, and entrepreneurs, who provide guidance and business connections that can't be replicated in any classroom.

Recipients of the fellowships are all aged 22 or under, and all possess highly impressive track records in entrepreneurship and technical innovation. A key demand of the program is that its awarded fellow 'skip or stop out' of higher education, or even school, and engage in self-directed technical research. Five years after being established in 2011, the program claims that Thiel Fellows have started over 60 companies that are together worth $\$ 1$.1billion. Recipients of the fellowship have been profiled in an online video series called Teen Technorati on the video channel of Wired magazine (https://www.wired.com/video/series/teen-technorati). Notably, in late 2016 Peter Thiel himself began advising President-elect Donald Trump by building a network of technology policy advisors, while many of the Thiel Fellows have formed into tight and influential networks whose association with Thiel is seen as important in brokering meetings with Silicon Valley investors (Hempel 2016).

The Thiel Fellowship also supports its fellows to approach technology incubator and accelerator programs like Y Combinator_(https://www.ycombinator.com/) and Imagine K-12

(http://www.imaginek12.com/), the sources of significant seed funding and mentorship for new Silicon Valley startups, including those dedicated to educational technology. Incubators help new startups to test and validate ideas, while accelerators turn products into scalable businesses, often through direct equity investment, and provide legal, technical and financial services along with mentorship, working space and access to educators, entrepreneurs, business partners and potential investors (Gomes 2015). These incubator and accelerator programs are themselves pedagogic in the sense that they provide on-the-job mentoring as a kind of apprenticeship into 
the cultural, technical and economic practices of Silicon Valley, and have themselves been integral to the growth of the educational technology sector in Silicon Valley since 2010 (EdSurge 2016).

New kinds of institutions such as 42, the Thiel Fellowships and accelerator programs represent a direct challenge to the existing higher education sector, and a significant acceleration in the pipeline model of education which sees learning in narrowly instrumental terms as high-tech vocational training for the software development industry. In this sense, these initiatives provide apprenticeship into the cultural and professional practices of Silicon Valley, while serving to marginalize the role of HE institutions to inculcate forms of critical questioning or other culturally-situated forms of inquiry. Much like Silicon Valley itself, its startup alternatives to higher education emphasize competition, intensive work practices, and technocratic forms of 'solutionism' which hold that all social problems can be solved with the right code and algorithms rather than through critical examination of the social, cultural, political and economic factors that structure everyday life (Morozov 2013). An emphasis on training teen technorati is treated as a solution to the problem of apprenticeship into the working culture of Silicon Valley itself, and simultaneously as a mechanism for training new apprentice solutionists.

\section{Building human capital through self-help}

Once any successful teen technorati or Stanford graduates have made it as far as a job in the Valley, the learning does not stop. For a start, many of the technical roles in Silicon Valley companies and startups require a formidable amount of learning as new programming languages, software packages and so on have to be mastered (Kitchin \& Dodge 2011). The kind of selfdirected education and highly competitive working environment promoted by 42 and the Thiel Fellowship are ways of enculturing young people to these pressures.

With its relentless demands for innovation, Silicon Valley is also a place where individuals are under pressure to innovate on themselves — to invest in making themselves as 'awesome' as possible (Ferenstein 2015). As a consequence, the self-help industry in Silicon Valley is booming. Kahn (2016) has documented the range of emerging self-help courses that have spread around the Valley's campuses. Many of these training curricula are based on insights from the field of behavioural economics, and emphasize how 'bad mental habits,' 'cognitive errors' and 'hidden failures' (such as procrastination, making poor investments, wasting time, fumbling important decisions, and avoiding problems) can be overcome through rationalist self-analysis. Such programs, argues Kahn (2016), have generated 'interest among data-driven tech people and entrepreneurs who see personal development as just another optimization problem.' Silicon Valley's self-help programs promise to enable users to be more 'intellectually dynamic and nimble' and to 'fix personal problems.'

Companies such as Google have been amongst the most enthusiastic promoters of these kind of technocratic self-help training courses, as part of its focus on 'employee performance optimization’ (Duhigg 2016). Popular Silicon Valley self-help initiatives translate psychological and behavioural economics insights into training curricula that are aimed at personal optimization. These training curricula encourage Valley workers to see themselves in rationalist terms as a programming problem —as a pattern of behaviours and rules in a complex system that, if analyzed hard enough, can be tweaked and modified to perform optimally., They view 
'the brain as a kind of second-rate computer, jammed full of old legacy software but possible to reprogram if you can master the code' Kahn (2016).

Self-help is thus a solution to yet another perceived problem-of suboptimal employee performance-and one that is itself exacerbated by the relentless culture of entrepreneurship, innovation and competition into which initiatives like 42 and the Thiel Fellowship enculturate young software developers. As a consequence, Silicon Valley is creating or endorsing new institutions and practices to educate and produce awesome and entrepreneurial innovators-like the 'self-programmable labour' influentially described by Castells (1996) that is equipped with the ability to retrain itself, and adapt to new tasks, new processes and new sources of information, as technology, demand, and management speed up their rate of change.

Ultimately, the task of educating Silicon Valley correlates with the reproduction of selfprogrammable labour that can retrain and optimize itself. Through its current reformatory efforts in education, Silicon Valley is seeking to create institutions that might be appropriate to the production of the entrepreneurial, self-programming individuals who will inhabit the next wave of the techno-economic revolution. For this to occur, it requires optimally functioning workers skilled in rational self-analysis and psychological debugging, not just technical upskilling. As Foucault (2008: 229) wrote in an influential lecture, the production of 'human capital' as 'abilities-machines that will produce income' relies on 'educational investments' such as school instruction and professional training, but also cultural stimuli, health, and psychological wellbeing, to enable individuals to see themselves as entrepreneurs of their selves:

If there is innovation, that is to say, if we find new things, discover new forms of productivity, and make technological innovations, this is nothing other than the income of a certain capital, of human capital, that is to say, of the set of investments we have made at the level of man himself. (Foucault 2008: 231)

The production of Silicon Valley human capital relies on educating individuals to see themselves not just as 'abilities-machines,' but in terms of 'individual enterprise, of enterprise of oneself with investments and incomes' (Foucault 2008, 230). Over and above a simple correspondence between education and labour, the production of human capital in Silicon Valley requires the inculcation of individuals into a whole way of life, certain technological practices, political inclinations, and commitments to ongoing self-optimization.

\section{Conclusion}

The task of educating Silicon Valley is one that involves varied actors, institutions, pedagogic practices, technologies, intellectual traditions, policy opportunities and curricula, all of which have combined into a durable network of coordinated things and actions. These diverse practices, styles of thinking and resources provide a kind of loose educative network of a new mode of educational provision, or an infrastructure of learning, that is intended as a form of investment to shape the knowledge, skills, cultural practices and ways of thinking of Silicon Valley human capital. These practices are integral to the ways that Silicon Valley has become intelligible in terms of concepts of technological innovation, entrepreneurialism, venture capital, and relentlessly optimistic faith in computational power to solve problems. Silicon Valley requires constant cycles of education and learning to ensure its continued competitive advantage in the techno-economic revolution it has catalysed and sustained over decades, and is therefore using education as a vehicle to reproduce its novel version of information capitalism. Indeed, Silicon Valley's current enthusiasm for investing in and reforming education could be 
understood as a way in which it is seeking to reproduce its own culture and values, not just within the Valley but beyond and at larger scale. It is a technological space that is being recast as a model for the social, political, and economic arrangement of state education. As distinctive products of this model, hackerspaces, startup schools, Stanford's 'hypernudge' labs, teen technorati programs and self-help courses are treated as prototypical templates and beta-tests for an emerging education reform movement, one supported by corporate technology companies, venture capital firms and emerging tech-centred venture philanthropies.

In sum, Silicon Valley's approach to education is being driven by several key ways of thinking:

- Distrust of state education, and a belief that the organization of state schooling and higher education is broken, bureaucratic and philosophically flawed

- Trust in markets to provide a competitive alternative to existing educational provision

- Confidence in the power of reformed education to drive innovation and thus lead to the solution to major social problems

- Emphasis on real-world problems, hands-on technical experience and practical learning

- Commitment to measurement and metrics in the assessment and evaluation of the performance of institutions

- Faith in data analytics and constant classroom surveillance to provide insights into student learning

- Belief that philanthropy and venture capital investment (and hybrid combinations of philanthrocapital) can provide the means to fix failing educational systems

- View that education constitutes a valuable market with high financial returns for investors in successful adaptive learning platforms

- Subscription to the idea that humans are sub-optimal computing machines that can be analysed for their psychological bugs and fixed through training and rational self-analysis

Several intellectual lines of thought can be detected here: the lingering progressivist commitment to experiential and student-centred learning, twinned with the administrative progressivism of measurement, efficiency and market-based reform; a trust in new tech-centred forms of both venture capital and philanthropic private sector funding; the emphasis of behavioural economics on humans' 'mental errors'; and the technocratic assumption that problems can be fixed better with technology than government intervention. The new educational models that Silicon Valley is beta-testing on itself and seeking to roll out and scale up represent the next step in the 'corporatization of public schools' - not just the 'transformation of the school on the model of the corporation' (Saltman 2010: 13), but more specifically the transformation of the school on the technical, economic, cultural and psychological model of Silicon Valley itself. Of course, there is nothing inevitable about the transformations to education that Silicon Valley envisages. In 2014, a major Gates Foundation-funded program to install a nationwide data platform in US public education, inBloom, collapsed despite over $\$ 83$ million funding after widespread concerns over student data protection and privacy (Bulger, McCormick \& Pitcan 2017). The consequence of the public backlash against inBloom is that newer Silicon Valley ventures have focused on small but scalable startup models in an effort to demonstrate their effectiveness, before rolling out via the extension of privately-run institutions and philanthropically-funded programs-as AltSchool, XQ Super School, 42, the Thiel Fellowship and so on all demonstrate. 
Critical cultural studies and educational sociology have long dealt with how the knowledge and culture of powerful social groups are transmitted through educational institutions, and how this process reproduces their social and cultural power. Through its infrastructure of high-tech homeschooling, startup schools, higher education partnerships, teen technorati fellowships and rationalist self-help programs, Silicon Valley is investing in itself through education in order to reproduce its powerful centrality in the current techno-economic revolution. It is also seeking to 'scale up' its innovations to 'disrupt' state education as a whole. As Selwyn (2016) has noted, the dominant Silicon Valley discourse of 'disruptive innovation' has become increasingly common in relation to technology in education, with small start-up firms and entrepreneurs seed-funded to develop alternative ways of doing things that might expand to invade and disrupt the existing established marketplace. The promise of market disruption and scalability underpins many of the initiatives, projects and programs which, driven by the new startup education ministries of Silicon Valley companies and entrepreneurs, are intended to expand into the existing marketplace of state education. In this sense, Silicon Valley is establishing itself as a new site of educational governance - a network of corporate education reformers seeking to exert influence and authority over state education at arms-length by translating diverse practices and allies into its own ambitions and practical projects.

To these ends, Silicon Valley has successfully juxtaposed itself on to the US homeschooling movement via hackerspaces and the maker movement, and in doing so aligned its aspirations with the long history of student-centred progressive education. As part of an emerging high-tech form of administrative progressivism, it has latched on to charter schools policies as a way of opening up new markets for its own startup schools and delivering new forms of data-driven and performance-focused personalized learning. It has mobilized higher education institutions such as Stanford to help educate young technical experts in the material practices and persuasive techniques of software development, while also directly supporting new skills-based alternatives to HE practices that might enculturate young software developers into the labour practices required by industry. It has also engaged with the Californian self-help movement to produce new kinds of hybrid programs that turn self-improvement into code-like debugging problems to solve via rational self-analysis and psychological optimization. Along the way, Silicon Valley entrepreneurs have built associations and affiliations with government officials, educational researchers and academics, school leaders and educators, and a range of educational 'thought leaders,' translating their diverse interests into a shared commitment to reform educational institutions and pedagogic practices in the image of the institutions and practices of Silicon Valley itself. These translations of diverse interests into practical developments are evidence of an emerging form of disruptive governance whereby Silicon Valley is seeking to govern educational institutions, practices and policies at a distance via its headquarters and their networks of affiliations rather than through state centres of government, in ways which are intended to reproduce its innovative and entrepreneurial capacities to sustain informational capitalism. The involvement of Silicon Valley entrepreneurs in education is emblematic of an increasing transferral of power away from democratic processes towards new sources of technical, economic and political expertise that represent a reshaping of public education by corporate reformers.

\section{References}


Bray, M. \& Kwo, O. 2013. Behind the façade of fee-free education: shadow education and its implications for social justice. Oxford Review of Education 39 (4), 480-497.

Bulger, M., McCormick, P. \& Pitcan, M. 2017. Assessing the legacy of inBloom. Data \& Society working paper, 2 Feb 2017: https://datasociety.net/pubs/ecl/InBloom_feb_2017.pdf

Castells, M. 1996. The Rise of the Network Society. Oxford: Blackwell.

Corcoran, B. \& Gomes, P. 2016. Can venture capital put personalized learning within reach of all students? EdSurge, 21 June 2016: https:/ /www.edsurge.com/news/2016-06-21-can-venture-capital-put-personalized-learning-withinreach-of-all-students?

Cuban, L. 2016. Draining The Semantic Swamp of "Personalized Learning"-A View from Silicon Valley (Part 1). Larry Cuban on School Reform and Classroom Practice, 20 June 2016:

https://larrycuban.wordpress.com/2016/06/20/draining-the-semantic-swamp-of-personalized-learning-a-viewfrom-silicon-valley-part-1/

Duff, A.S. 2016. Rating the revolution: Silicon Valley in normative perspective. Information, Communication and Society. DOI: $10.1080 / 1369118 X .2016 .1142594$

Duhigg, C. 2016. What Google learned from its quest to build the perfect team. New York Times Magazine, 28 February 2016: http://www.nytimes.com/2016/02/28/magazine/what-google-learned-from-its-quest-to-buildthe-perfect-team.html

Education Week. 2016. Examining Mark Zuckerberg's New K-12 Giving Strategy. Education Week, 7 March 2016 : http://www.edweek.org/ew/projects/chan-zuckerberg-initiative-package.html

EdSurge. 2016. Following Edtech Money: How does money shape the K-12 edtech sector? The State of Edtech 2016: How Money Shapes Tools and Schools. EdSurge: https://www.edsurge.com/research/special-reports/state-of-edtech2016/funding

Ferenstein, G. 2015. The Age of Optimists: A quantitative glimpse of how Silicon V alley will transform politics and everyday life: https://medium.com/the-ferenstein-wire/silicon-valley-s-political-endgame-summarized-1f395785f3c1

Fogg, B. J. 2002. Persuasive Technology: Using Computers to Change What We Think and Do. Ubiquity, December 2002: $89-120$

Foucault, M. 2008. The Birth of Biopolitics: Lectures at the College de France, 1978-1979. Trans. G. Burchell. New York: Palgrave Macmillan.

Gomes, P. 2015. Your Guide to a Nation of Edtech Accelerators. EdSurge, 21 October 2015:

https://www.edsurge.com/news/2015-10-21-your-guide-to-a-nation-of-edtech-accelerators

Halverson, E.R. \& Sheridan, K. 2014. The maker movement in education. Harvard Educational Review 84 (4): http://hepg.org/her-home/issues/harvard-educational-review-volume-84-number-4/herarticle/the-makermovement-in-education

Hempel, J. 2016. The Peter Thiel Pedigree. Backechannel, 7 December 2016: https://backchannel.com/inside-peterthiels-genius-factory-7bf38303c7be\#.re7i0x6vm

Herold, B. 2016. Zuckerberg, Chan Tap James Shelton to Lead Huge Education Giving Effort. Education Week, 4 May 2016: blogs.edweek.org/edweek/DigitalEducation/2016/05/zuckerberg_chan_shelton_philanthropy.html

Jones, R., Pykett, J. \& Whitehead, M. 2013. Changing Behaviours: On the rise of the psychological state. Cheltenham: Edward Elgar.

Kane, P. 2016. Leading Brexiteers are pining for all of us to embrace a life built on havoc. The National, 18 June 2016: http://www.thenational.scot/comment/pat-kane-leading-brexiteers-are-pining-for-all-of-us-to-embrace-alife-built-on-havoc. 18931 
Kahn, J. 2016. The Happiness Code. New York Times Magazine, 14 January 2016:

http://www.nytimes.com/2016/01/17/magazine/the-happiness-code.html

Kitchin, R. \& Dodge, M. 2011. Code/Space: Software and everyday life. London: MIT Press.

Kuchler, H. 2017. Inside Silicon Valley's classrooms of the future. FT Magazine, 3 February 2017:

https://www.ft.com/content/d629e512-e805-11e6-967b-c88452263daf

Lapowsky, I. 2015. Inside the school Silicon Valley thinks will save education. Wired, 4 May 2015:

http://www.wired.com/2015/05/altschool/

Lapowsky, I. 2016. The 2016 election exposes the very, very dark side of tech. Wired, 7 November 2016: https://www.wired.com/2016/11/2016-election-exposes-dark-side-tech/

Lee, T.B. \& Ferenstein, G. 2016. 'Libertarian but very pro-government': the distinctive ideology of Silicon Valley. Vox, 19 February 2016: http://www.vox.com/2016/2/19/11057836/silicon-valley-democrat-explained

Lewis-Krause, G. 2016. The Great AI Awakening. The New York. Times Magazine, 14 December 2016: http://www.nytimes.com/2016/12/14/magazine/the-great-ai-awakening.html

Lubienski, C. 2013. Privatising form or function? Equity, outcomes and influence in American charter schools. Oxford Review of Education 39 (4), 498-513.

Lubienski, C., Puckett, T. \& Jameson Brewer, T. 2013. Does Homeschooling “Work"? A Critique of the Empirical Claims and Agenda of Advocacy Organizations. Peabody Journal of Education 88 (3), 378-392.

Morozov, E. 2013. To Save Everything, Click Here: Technology, solutionism and the urge to fix problens that don't exist. London: Allen Lane.

Reckhow, S. 2013. Follow the Money: How Foundation Dollars Change Public School Politics. New York: Oxford University Press

Ribbhagen, C. 2011. What makes a technocrat? Explaining variation in technocratic thinking among elite bureaucrats. Public Policy and Administration 26 (1), 21-44.

Roberts-Mahoney, H., Means, A.J. \& Garrison, M.J. 2016. Netflixing human capital development: personalized learning technology and the corporatization of K-12 education. Journal of Education Policy: http:/ /dx.doi.org/10.1080/02680939.2015.1132774

Robertson, J., Riley, M. \& Willis, A. 2016. How to hack an election. Bloomberg, 31 March 2016: http://www.bloomberg.com/features/2016-how-to-hack-an-election/

Saltman, K. 2016. Corporate schooling meets corporate media: Standards, testing, and technophilia, Review of Education, Pedagogy, and Cultural Studies 38 (2), 105-123.

Selwyn, N. 2016. Is Technology Good for Education? Cambridge: Polity.

Suoranta, J. \& Vaden, T. 2010. Wikiworld. London: Pluto Press.

Tanz, J. 2015a. The Techies Who Are Hacking Education by Homeschooling Their Kids. Wired, 2 April 2015: http://www.wired.com/2015/02/silicon-valley-home-schooling/

Tanz, J. 2015b. The Tech Elite's Quest to Reinvent School in Its Own Image. Wired, 26 October 2015: http://www.wired.com/2015/10/salman-khan-academy-lab-school-reinventing-classrooms/

Trikha, R. 2015. The Interdependency of Stanford and Silicon Valley. TechCrunch, 4 September 2015: http:/ /techcrunch.com/2015/09/04/what-will-stanford-be-without-silicon-valley/

Wan, T. \& McNally, T. 2015. Education Technology Deals Reach \$1.6 Billion in First Half of 2015. EdSurge, 29 July 2015: https:/ /www.edsurge.com/news/2015-07-29-education-technology-deals-reach-1-6-billion-in-first-half-of2015 
Watters, A. 2015. Ed-tech and the Californian ideology. Hack Education, 17 May 2015:

http://hackeducation.com/2015/05/17/ed-tech-ideology

Weisberg, J. 2016. We are hopelessly hooked. The New York Review of Books, 25 February 2016:

http://www.nybooks.com/articles/2016/02/25/we-are-hopelessly-hooked/

Wildman, S. 2016. British Power Broker Steve Hilton Sets His Sights on Washington. New York Times, 13 May 2016 : http://www.nytimes.com/2016/05/15/fashion/steve-hilton-more-human.html?_r=0

Woolley, S. 2016. Automating power: social bot interference in global politics. First Monday 21 (4): http://firstmonday.org/ojs/index.php/fm/article/view/6161/5300

Yeung, K. 2016. Hypernudge: big data as a mode of regulation by design. Information, Communication and Society: http://dx/doi.org/10.1080/1369118X.2016.1186713 